\title{
AQUATIC AND TERRESTRIAL STRESSORS IN AMPHIBIANS: A TEST OF THE DOUBLE JEOPARDY HYPOTHESIS BASED ON MATERNALLY AND TROPHICALLY DERIVED CONTAMINANTS
}

\author{
Brian D. Todd, $* \dagger \ddagger$ Christine M. Bergeron $\ddagger$ Mark J. Hepner, $\ddagger$ and William A. Hopkins $\ddagger$ \\ $\dagger$ University of California, Davis, Department of Wildlife, Fish, and Conservation Biology, Davis, California, USA \\ $\ddagger$ Department of Fish and Wildlife Conservation, Virginia Tech, Blacksburg, Virginia, USA
}

(Submitted 15 March 2011; Returned for Revision 25 April 2011; Accepted 29 June 2011)

\begin{abstract}
Amphibians with biphasic life histories occupy aquatic and terrestrial habitats at different times in their lives, leading to a double jeopardy of contaminant risk in both habitats. The present study examines individual and interactive effects of mercury exposure to terrestrial adults and aquatic larvae on fitness-related traits of American toads, Bufo americanus. Eggs from reference mothers or contaminated mothers were allowed to hatch and larvae were fed diets of either no added $\mathrm{Hg}$ or $2.5 \mathrm{or} 10 \mu \mathrm{g} / \mathrm{g}$ total $\mathrm{Hg}$ (dry wt). Both dietary and maternal $\mathrm{Hg}$ had adverse effects on developing larvae, but there was no interaction between these factors. Dietary $\mathrm{Hg}$ had a marginal effect of decreased survival with increasing $\mathrm{Hg}$ in the diet. Animals from $\mathrm{Hg}$-exposed mothers weighed $14 \%$ less than those from reference mothers, and size at metamorphosis was directly correlated with hopping performance. Animals from $\mathrm{Hg}$-exposed mothers also took longer to complete metamorphosis and had 2.5 times the prevalence of spinal malformations compared with those from reference mothers. Results of the present study demonstrate that amphibians do indeed face a double jeopardy of contaminant exposure stemming from terrestrial and aquatic environments, because both exposure pathways adversely affected developing offspring. The present study also demonstrates that all possible routes of exposure over an organism's life history must be examined to provide a comprehensive picture of the ecological consequences of habitat contamination. Environ. Toxicol. Chem. 2011;30:2277-2284. (C) 2011 SETAC
\end{abstract}

Keywords-Amphibian declines Bufo americanus Dietary exposure Maternal transfer $\quad$ Mercury

\section{INTRODUCTION}

Organisms may be exposed to environmental contaminants in several habitats over the course of their lives, depending on their life history, behavior, and ecology. This is particularly true for migratory species, which may rear young in habitats distinct from adult feeding or over-wintering grounds. For example, migratory white-faced ibis (Plegadis chihi) produce eggs contaminated with dichlorodiphenyldichloroethylene at uncontaminated nesting grounds [1]. Contamination of the eggs was traced to prior exposure of foraging parents in distant wintering habitats and resulted in reduced reproductive success [1]. Thus, although the young did not feed directly on contaminated forage after hatching, surviving hatchlings bore a legacy dichlorodiphenyldichloroethylene burden as a result of the migratory life history of their parents.

Many vertebrates are migratory and have lives that span two or more discrete habitats or geographic regions. However, amphibians with biphasic life histories perhaps best embody the complete compartmentalization of habitats that can occur in migratory species, because they occupy aquatic habitats as larvae and terrestrial habitats after metamorphosis [2]. This dual reliance on separate aquatic and terrestrial habitats has led some authors to suggest that biphasic amphibians face a "double jeopardy" of exposure risk to environmental contaminants via both aquatic and terrestrial pathways [3]. Despite concern over this double jeopardy and the possible role that environmental contaminants play in global amphibian declines [4],

\footnotetext{
* To whom correspondence may be addressed (btodd@ucdavis.edu).

Published online 13 July 2011 in Wiley Online Library (wileyonlinelibrary.com).
}

most studies have focused solely on embryonic or larval exposure to contaminants and have not examined the consequences of exposure in terrestrial life stages [5].

Exposure to environmental contaminants in terrestrial life stages may affect individual fitness directly, by reduced survival or reproductive success of adults, or indirectly, by transgenerational effects on offspring. Previous studies have demonstrated that accumulation of metals in adult amphibians can lead to maternal transfer of contaminants to eggs and directly influence reproductive success [6,7]. However, few attempts have been made to determine how amphibian offspring are affected by the accumulation of environmental contaminants in their terrestrial parents via transgenerational effects [8]. Because amphibian larvae may face a double jeopardy of contaminant exposure from both terrestrial (by parental effects) and aquatic (by dietary or aqueous exposure) environments, it is critical to evaluate the relative contributions of these exposure pathways to individual fitness. Such evaluations will be particularly important for identifying additive or synergistic interactions of aquatic and terrestrial contaminant exposure. For example, terrestrial adults may accumulate environmental contaminants from exposure in the terrestrial environment [6,7], but they can also directly influence the postnatal environment of developing offspring by ovipositing in either contaminated or uncontaminated aquatic sites.

The present study follows previous research documenting mercury accumulation in American toads (Bufo americanus) inhabiting an industrially contaminated flood plain along the South River, Virginia, USA [9]. We previously found that $\mathrm{Hg}$ accumulation in terrestrial females resulted in reduced body size of offspring $[10,11]$. In addition, by feeding offspring from $\mathrm{Hg}$-contaminated or reference mothers three levels of dietary 
$\mathrm{Hg}$, we found that body size was also negatively affected by dietary $\mathrm{Hg}$ and that the experimental cross of maternal $\mathrm{Hg}$ and high dietary $\mathrm{Hg}(10 \mu \mathrm{g} / \mathrm{g}$, dry wt total $\mathrm{Hg})$ caused a significant reduction in offspring survival [11]. However, the required study design in Bergeron et al. [11] precluded any investigation of malformation frequency, a common developmental aberration resulting from metal exposure [12]. Also, too few animals completed metamorphosis to allow us to examine postmetamorphic performance or survival in the terrestrial environment. We raised offspring communally in large, replicated containers separated for each experimental cross of maternal group by dietary treatment so that we could investigate the consequences of terrestrial adult exposure and aquatic larval exposure, independently and interactively, on fitness-related traits (size, survival, developmental timing, malformation frequency, and postmetamorphic locomotor performance). In a follow-up study, we will report on postmetamorphic survival of the animals used in the present study one year after metamorphosis. Because $\mathrm{Hg}$ is a neurotoxicant and can affect the endocrine and reproductive systems of vertebrates [13-15], we predicted that both maternal and dietary $\mathrm{Hg}$ would negatively affect body size, developmental time, postmetamorphic hopping performance, and survival of American toad offspring. We also predicted that malformation frequency would increase with dietary $\mathrm{Hg}$ and would be greater in offspring from $\mathrm{Hg}$-exposed mothers. Our study design allowed us to address the degree to which amphibians with biphasic life histories truly face double jeopardy from contaminant exposure by combined terrestrial and aquatic pathways as well as to identify whether the interaction of the two pathways has more pronounced negative effects on offspring than either exposure alone.

\section{MATERIALS AND METHODS}

\section{Study species}

The American toad, B. americanus, is found across much of northern and eastern North America. The species is generally highly terrestrial but must return to water to breed, where females produce clutches of 5,000 to 15,000 eggs. The larval period is relatively short and lasts for approximately 25 to $90 \mathrm{~d}$ as tadpoles forage on algae and plant matter. After metamorphosis, individuals leave the water and live terrestrially for approximately five years or more [16], feeding on insects and other invertebrates.

\section{Study site}

The South River is located in the Shenandoah Valley (Virginia, USA) and was historically (1929-1950) contaminated with mercuric sulfate via point-source inputs from an industrial plant manufacturing acetate fiber in Waynesboro (VA, USA). Amphibians that inhabit the contaminated portion of the South River, including American toads, have elevated $\mathrm{Hg}$ concentrations in their tissues compared with conspecifics from nearby reference sites upstream [9]. Other studies in this system have demonstrated $\mathrm{Hg}$ accumulation in both the aquatic and the terrestrial food webs, indicating dispersed contamination along the flood plain and terrestrial habitat downstream from the historic contaminant source [17-19]. A prior study of surface water and sediment along the South River confirmed that $\mathrm{Hg}$ is the primary contaminant, whereas organochlorine pesticides, polycyclic aromatic hydrocarbons, and metals other than $\mathrm{Hg}$ are generally low (URS Corporation, 2007, Virginia Beach, VA, USA, unpublished data). Physical habitat both upstream and downstream from the historic contaminant source is generally similar, being composed mainly of old fields and small, interspersed riparian strips of deciduous forest along the river.

\section{Experimental diet}

The experimental diets fed to toad larvae consisted of a mixed dry feed spiked with or without $\mathrm{Hg}$ (both inorganic mercury, $\mathrm{HgII}$ and organic methylmercury, $\mathrm{MeHg}$ ) and suspended in an agar-gelatin mixture similar to that used by Unrine and Jagoe [20]. The resulting diet was a semisolid matrix that allowed the larvae to graze as they would naturally while preventing the diet from dissolving. The control diet treatment contained no added $\mathrm{Hg}$. The target total $\mathrm{Hg}$ ( $\mathrm{THg}$ ) concentration for the low- $\mathrm{Hg}$ treatment was $2.5 \mu \mathrm{g} / \mathrm{g}$, dry weight $(2.75 \%$ $\mathrm{MeHg}$ ). This concentration corresponds to approximately twice the highest measured $\mathrm{THg}$ concentrations in the guts of larval southern leopard frogs (Rana sphenocephala) from ephemeral wetlands in the southeastern United States receiving $\mathrm{Hg}$ solely from atmospheric deposition [21]. The target $\mathrm{THg}$ concentration for the high-Hg treatment was $10 \mu \mathrm{g} / \mathrm{g}$ dry weight $(1.05 \%$ $\mathrm{MeHg}$ ). This corresponds to the upper limits of $\mathrm{Hg}$ concentrations found in periphyton at the $\mathrm{Hg}$-contaminated South River, Virginia (K.R. Tom, 2008, Master's thesis, The College of William and Mary, Williamsburg, VA, USA). Total Hg concentrations in the diets were attained by adding mercury (II) chloride and methylmercury (II) chloride based on equations in the article by Unrine and Jagoe [20]. Briefly, dry components (vitamin-enriched rabbit pellets [Classic Blend Rabbit Food, L/M Animal Farms; $218 \mathrm{~g}$ ], trout pellets [Aquamax Grower 600, PMI Nutrition International; $218 \mathrm{~g}$ ], fish flakes [TetraMin, Tetra, $32 \mathrm{~g}$ ], and algae powder [SeraMicron, Sera, $32 \mathrm{~g}$ ]) were ground and homogenized. Ethanol (95\%) with or without $\mathrm{Hg}$ was added to the dry components, homogenized, and dried under a fume hood. Once the mixture was dry, we combined nanopure water $(750 \mathrm{ml})$, agar $(20 \mathrm{~g})$ and gelatin (14 g) while stirring and heating the solution to approximately $70^{\circ} \mathrm{C}$ on a hotplate. This solution was poured over the dry components, mixed until homogenized, and cooled. Experimental diets were stored in $\mathrm{a}-80^{\circ} \mathrm{C}$ freezer until use. Uniform rations were prepared by pressing the thawed diet out of a syringe and cutting into equal lengths of known mass. The coefficient of variation for diet pieces cut to a standard length averaged $4.9 \%$ among various ration sizes.

\section{Field collection and experimental design}

On April 17 and 18, 2009, we collected reproductive pairs of American toads from breeding pools in the South River flood plain at three locations, including an uncontaminated reference site upstream and two contaminated sites downstream from the source of $\mathrm{Hg}$ [10]. We collected pairs that had entered amplexus but had not yet begun ovipositing and brought them into the laboratory, where they were allowed to breed overnight in shallow, inclined bins with dechlorinated tap water. The next morning, we removed the adult toads from the bins, counted their eggs, and added additional dechlorinated tap water to the egg masses. We removed and froze a small portion of each egg mass $(\sim 500$ eggs $)$ to determine later the concentration of $\mathrm{Hg}$ transferred maternally. Following the methods of Bergeron et al. [7], we collected approximately $0.25 \mathrm{ml}$ of whole blood from each anesthetized mother via cardiocentesis to quantify $\mathrm{THg}$ concentrations. Finally, we recorded mass and snout-vent length of the adult toads, marked them by toe clipping, and released them at their point of capture within $24 \mathrm{~h}$ after they had recovered from anesthesia. 
We analyzed female blood $\mathrm{THg}$ concentrations before the eggs hatched to confirm placement of hatchlings into experimental groups based on the known correlation between female blood THg concentrations and those of eggs [7]. The reference group of larvae and the group exposed to maternal $\mathrm{Hg}$ (hereafter, maternally $\mathrm{Hg}$ exposed) included hatchlings from females with blood THg concentrations $<250$ and $>1,000 \mathrm{ng} / \mathrm{g}$, wet weight, respectively. Offspring used in the reference and maternally $\mathrm{Hg}$-exposed groups originated from five and six combined clutches, respectively. We maintained eggs in 10-L aquaria and replaced half of the water with fresh dechlorinated tap water each day until the eggs hatched. Morphologically normal hatchlings were then drawn in a stratified random fashion from each maternal clutch so that clutches were evenly represented in their maternal experimental groups.

We used a $2 \times 3$ factorial experimental design to test the individual and interactive effects of maternal $\mathrm{Hg}$ (reference and exposed) and dietary $\mathrm{Hg}$ (control, low, and high diet) on the larval development of American toads raised in a communal environment. Thus, we had six total experimental crosses. We allocated 50 four-day-old hatchlings into 36 experimental replicates on April 28, 2009. Each polypropylene bin containing 50 animals measured $86.6 \times 46 \times 40.4 \mathrm{~cm}$ and contained approximately $60 \mathrm{~L}$ dechlorinated tap water. Every $9 \mathrm{~d}$, we randomly drew 10 larvae from each of the 36 bins and weighed them to adjust food rations to account for growth. We also adjusted food rations to account for reduced density resulting from mortality or metamorphosing animals. We inspected all bins daily to remove any dead individuals. Each bin was supplied with rations equivalent to $9 \%$ of the total larval mass in each bin per day (wet wt basis) every $3 \mathrm{~d}$. All bins were housed in the same climate-controlled room and interspersed in a stratified fashion with respect to treatment. They were kept under a 12:12-h light:dark photoperiod with ambient temperature maintained at $18 \pm 3^{\circ} \mathrm{C}$. Every $3 \mathrm{~d}$, we exchanged $40 \%$ of the water in each bin with fresh dechlorinated water. At this time, accumulated feces and uneaten food were removed and fresh food was provided. Before every third water change, water in each of the bins was analyzed for nitrate, nitrite, temperature, $\mathrm{pH}$, and dissolved oxygen.

As larvae neared metamorphosis, they were checked at 12-h intervals for front limb emergence (Gosner stage [GS] 42). Upon emergence of the front limbs, larvae were removed from the bins, weighed, measured, and placed in individual 500-ml cups with approximately $20 \mathrm{ml}$ water from their bin and an unbleached paper towel to allow them to climb out of the water during tail resorption. We noted the presence of any gross spinal malformations at this stage, prior to the animals beginning tail resorption. Metamorphosing larvae in cups were also checked at 12-h intervals for completion of tail resorption (GS 46) or mortality. The first larva began metamorphosis on June 6 , 2009. In addition to quantifying the proportion of individuals that successfully completed metamorphosis in each treatment, we also determined mass and size at GS 42 and 46, the duration of the larval period to GS 42, and the time required for complete tail resorption (time between GS 42 and GS 46). All surviving metamorphosed toads, except for those to be used in additional postmetamorphic studies, were euthanized with buffered tricaine methane sulfonate (MS-222) $24 \mathrm{~h}$ after completing metamorphosis and then frozen for later $\mathrm{Hg}$ tissue analyses.

\section{Postmetamorphic hopping performance}

Presumably, if $\mathrm{Hg}$ deleteriously affects physical performance in recently metamorphosed toads or alters their flight response as a result of neurological impacts on behavior, this should be identifiable using an objective and repeatable measure of physical performance. Thus, we used methods similar to Goater et al. [22] to compare hopping performance objectively in recently metamorphosed toads. During the peak frequency of metamorphosis, we haphazardly selected three to six individuals from each replicate for hopping performance trials. Within $24 \mathrm{~h}$ of completing tail resorption, each recently metamorphosed toad was placed on a clean, dry platform and gently nudged on the urostyle to elicit a flight response. We marked and measured the length of the first four hops and calculated a mean hop length for each individual. The mean hop lengths of each individual within a replicate bin were averaged to produce a representative mean hop length for each replicate bin.

\section{Mercury tissue analyses}

In a previous study, Bergeron et al. [7] determined that $71.4 \pm 2.8 \%$ (mean \pm 1 standard error hereafter) of $\mathrm{THg}$ in the blood and $47.8 \pm 3.3 \%$ of $\mathrm{THg}$ in eggs was in the form of $\mathrm{MeHg}$. Therefore, we analyzed only $\mathrm{THg}$ in blood and eggs in the present study. We homogenized whole blood from each female American toad using a vortex mixer, and we report $\mathrm{THg}$ concentrations of blood on a wet weight basis. We lyophilized and homogenized eggs and report $\mathrm{THg}$ concentrations of eggs on a dry-weight basis. Percentage moisture of eggs was $95.4 \pm 0.2 \%$. We analyzed subsamples of the homogenized tissues ( $\sim 20 \mathrm{mg}$ ) for $\mathrm{THg}$ content by combustion-amalgamation-cold vapor atomic absorption spectrophotometry (Direct Mercury Analyzer 80, Milestone) according to U.S. Environmental Protection Agency method 7473 [23]. For quality assurance, each group of 10 to 15 samples included a replicate, blank, and standard reference material (SRM; DORM-3 fish protein and DOLT-3 or DOLT-4 dogfish liver [National Research Council of Canada, Ottawa, Ontario, Canada]). We calibrated the instrument using solid SRMs (DORM-3 and DOLT-3 or DOLT-4). The method detection limit (MDLs; three times standard deviation of procedural blanks) for samples was $0.39 \mathrm{ng}$, and all samples had $\mathrm{THg}$ concentrations that exceeded the limit. Average relative percentage differences between replicate sample analyses were $7.42 \pm 2.74 \%$ $(n=11)$. Mean percentage recoveries of THg for the SRMs, DORM-3, DOLT-3, and DOLT-4 were $107.82 \pm 1.15 \%$ $(n=23), \quad 99.66 \pm 0.51 \% \quad(n=12), \quad$ and $\quad 99.46 \pm 0.53 \%$ $(n=10)$, respectively.

We quantified $\mathrm{THg}$ and $\mathrm{MeHg}$ in the experimental diets and recently metamorphosed toads. For each diet, we lyophilized and homogenized three samples. For the recently metamorphosed toads, we created three composite samples for each experimental cross, and we lyophilized and homogenized each composite sample. Our composite samples were composed of one recently metamorphosed toad from each of the six replicate bins for each experimental cross. We report $\mathrm{Hg}$ concentrations of the diet and recently metamorphosed toads on a dry-weight basis. Percentage moisture of the diet and recently metamorphosed toads was $58.6 \pm 0.4 \%$ and $90.4 \pm 0.3 \%$, respectively. Samples were then analyzed for $\mathrm{HgII}$ and $\mathrm{MeHg}$ by Quicksilver Scientific using acidic thiourea leaching and $\mathrm{Hg}$-thiourea liquid chromatography coupled to cold-vapor atomic fluorescence spectrometry [24]. This method separates monomethyl $\left(\mathrm{CH}_{3} \mathrm{Hg}^{+}\right)$from mercuric (HgII) mercury by the charges in their thiourea complexes; online cold-vapor generation follows separation with an instrument detection limit of $4 \mathrm{pg} / \mathrm{g}$ for $\mathrm{MeHg}$ and $7 \mathrm{pg} / \mathrm{g} \mathrm{HgII} \mathrm{(for} \mathrm{a} \mathrm{100-mg} \mathrm{sample).} \mathrm{For} \mathrm{our} \mathrm{samples,}$ 
average relative percentage differences between replicate sample analyses were $3.94 \pm 0.69 \%$ for $\mathrm{MeHg}$ and $6.26 \pm 2.22 \%$ for $\mathrm{HgII}(n=6)$. Mean percentage recoveries of $\mathrm{MeHg}$ and $\mathrm{HgII}$ for matrix spikes were $92.85 \pm 0.49 \%$ and $103.40 \pm 2.04 \%(n=6)$, respectively. Also, mean percentage recoveries for the SRMs, DOLT-3 $(n=3)$ and BCR-463 (tuna fish [Institute for Reference Materials and Measurements, Geel, Belgium]; $n=3$ ) were $98.97 \pm 4.32 \%$ and $99.00 \pm 4.54 \%$ for $\mathrm{MeHg}$ and $104.43 \pm 5.81 \%$ and $101.37 \pm 4.46 \%$ for $\mathrm{THg}$.

\section{Statistical analyses}

We used nonparametric Mann-Whitney $U$ tests to compare blood and egg $\mathrm{THg}$ concentrations of reference and $\mathrm{Hg}$-exposed females, because they were not normally distributed. We used a multivariate analysis of variance (MANOVA) to test for effects of diet, maternal $\mathrm{Hg}$ exposure, and their interaction on $\mathrm{MeHg}$ and $\mathrm{HgII}$ concentrations in recently metamorphosed toads.

We used an analysis of variance (ANOVA) to compare masses of reference mothers and $\mathrm{Hg}$-exposed mothers and to compare clutch sizes between the two groups. We used an ANOVA to determine whether mean mass of larvae from reference clutches $(n=5)$ and maternally exposed clutches $(n=6)$ differed at the start of the experiment. We used Pearson correlations to determine whether maternal mass was correlated with mean larval mass for each clutch at the start of the experiment.

We used a MANOVA to test the effects of diet, maternal $\mathrm{Hg}$ exposure, and their interaction on the following endpoints: survival to GS 46, mass at GS 42, mass at GS 46, days for tail resorption, and the number of GS 42 tadpoles with spinal malformations. We calculated the mean of each endpoint for each replicate (bin), and these means were our statistical units. We applied a Box-Cox power transformation to spinal malformations to normalize the data. Data on the average time to GS 42 (larval length) were not normally distributed and could not be normalized with any transformations. Therefore, effects of diet, maternal $\mathrm{Hg}$ exposure, and their interaction on this endpoint were tested using the highly conservative nonparametric factorial Scherer-Ray-Hare test [25]. Finally, we used an analysis of covariance to test the effects of diet, maternal $\mathrm{Hg}$ exposure, and their interaction on the mean hop length of postmetamorphic toads, using body size (snout-vent length) as a covariate.

\section{RESULTS}

\section{Mercury concentrations}

As described in Materials and Methods, clutches were placed into either reference or contaminated groups depending on whether they came from the reference site or one of the contaminated sites. As a result, blood $\mathrm{THg}$ concentrations of reference females $(159.5 \pm 18.6 \mathrm{ng} / \mathrm{g}$ wet $\mathrm{wt})$ were significantly lower than those of contaminated females $(2,250 \pm 489.8 \mathrm{ng} / \mathrm{g}$ wet wt; $Z=-2.74, p=0.006)$. Egg THg concentrations from reference mothers $(20.6 \pm 1.3 \mathrm{ng} / \mathrm{g}$ dry wt) were also significantly lower than those from contaminated mothers (149.1 $\pm 17.9 \mathrm{ng} / \mathrm{g}$ dry wt; $Z=-2.71, p=0.006)$. Total $\mathrm{Hg}$ concentrations in diets were $0.010 \pm 0.001 \mu \mathrm{g} / \mathrm{g}$ dry wt $(56.7 \pm 5.5 \% \mathrm{MeHg}), 2.50 \pm 0.06 \mu \mathrm{g} / \mathrm{g}$ dry wt $(3.19 \pm 0.03 \%$ $\mathrm{MeHg})$, and $10.13 \mu \mathrm{g} / \mathrm{g} \pm 2.27$ dry wt $(1.05 \pm 0.01 \% \mathrm{MeHg})$ for the control, low-Hg, and high- $\mathrm{Hg}$ diets, respectively.

We found a significant effect of maternal $\mathrm{Hg}$, diet, and their interaction on tissue concentrations of $\mathrm{Hg}$ in recently metamorphosed American toads in our overall MANOVA (Fig. 1;

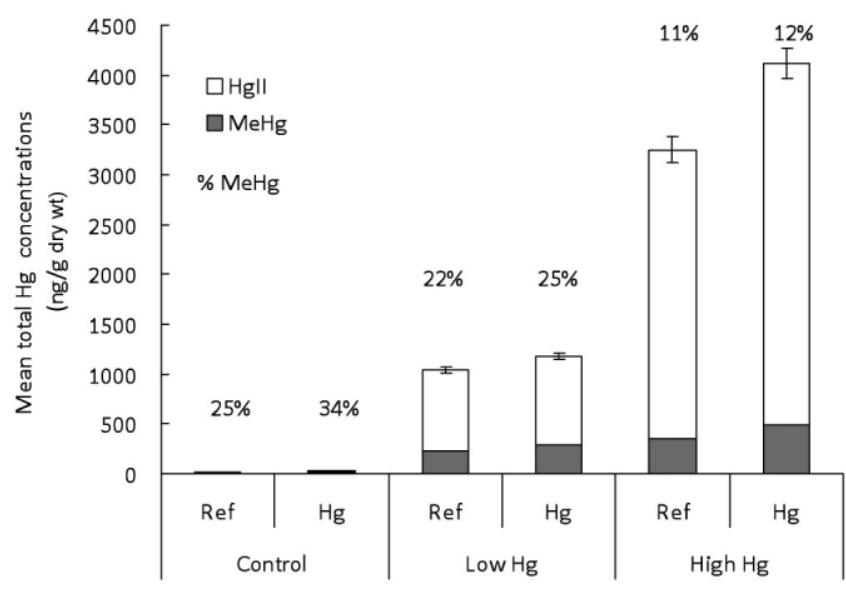

Fig. 1. Whole-body mercury (Hg) tissue concentrations (mean \pm standard error) of recently metamorphosed American toads. Larvae from either reference or $\mathrm{Hg}$-exposed mothers were fed control diet with no added $\mathrm{Hg}$, a low-Hg diet averaging $2.5 \mu \mathrm{g} / \mathrm{g}$ total $\mathrm{Hg}$ dry wt, or a high- $\mathrm{Hg}$ diet averaging $10.1 \mu \mathrm{g} / \mathrm{g}$ total $\mathrm{Hg}$ dry wt. There was a significant effect of maternal $\mathrm{Hg}$ $(p=0.001)$, dietary $\mathrm{Hg}(p<0.001)$, and their interaction on $\mathrm{Hg}$ tissue concentrations $(p=0.001) . \quad \mathrm{MeHg}=$ methylmercury; $\mathrm{HgII}=$ inorganic mercury.

maternal Hg: Pillai's trace $=0.71, F_{2,11}=13.49, p=0.001$; diet: Pillai's trace $=1.94, F_{4,24}=190.58, p<0.001$; interaction: Pillai's trace $\left.=1.07, F_{4,24}=6.94, p=0.001\right)$. In all cases, individual component ANOVAs identified significant effects of maternal $\mathrm{Hg}$, diet, and their interaction on both $\mathrm{MeHg}$ and $\mathrm{HgII}$ concentrations $(p<0.01)$. Increasing concentrations of $\mathrm{Hg}$ in the diet resulted in corresponding increases in the concentration of $\mathrm{Hg}$ in toads. Metamorphosed toads from $\mathrm{Hg}$-exposed mothers also had significantly greater $\mathrm{Hg}$ concentrations, an effect that was most pronounced when animals were fed the high-Hg diet. Mean percentage $\mathrm{MeHg}$ in the recently metamorphosed toads decreased with increasing $\mathrm{THg}$ concentration in diet. Post hoc Tukey tests revealed that $\mathrm{Hg}$ tissue concentrations in recently metamorphosed toads differed among all three diets for both $\mathrm{MeHg}$ and $\mathrm{HgII}(p<0.001)$.

\section{Biological variables}

Mothers collected from the $\mathrm{Hg}$-contaminated sites were marginally significantly smaller than those from the reference site $\left(F_{1,9}=4.5, p=0.06\right)$. However, mean larval mass and maternal mass were not correlated $(r=0.03, p=0.94)$, and larval mass between the two maternal groups did not differ significantly at the start of the experiment $\left(F_{1,9}=0.6\right.$, $p=0.47)$. In addition, no significant difference was noted in the mean number of eggs per clutch from $\mathrm{Hg}$-exposed $(7,196.8 \pm 442 ; 1$ standard error $[\mathrm{SE}])$ versus reference mothers $\left(6,614.6 \pm 284 ; 1 \mathrm{SE} ; F_{1,9}=1.05, p=0.32\right)$.

Overall, our MANOVA identified a significant adverse effect of both dietary and maternal $\mathrm{Hg}$ on developing larvae, but no evidence of an interaction between these factors (diet: Pillai's trace $=0.543, F_{10,54}=2.01, p=0.05$; maternal $\mathrm{Hg}$ exposure: Pillai's trace $=0.696, F_{5,26}=11.9, p<0.001$; interaction: Pillai's trace $\left.=0.281, F_{10,54}=0.88, p=0.554\right)$. Most component tests of the effects of diet had $p$ values $>0.19$, suggesting that the significant effect of diet in the overall MANOVA was attributable largely to the variance properties of the combined endpoints rather than to a single strong effect on any single endpoint. However, a marginally significant effect of decreased survival to GS 46 was noted as dietary $\mathrm{Hg}$ increased (Fig. $2 ; F_{2,30}=2.79, p=0.077$ ). In contrast, we found strong evidence that maternal $\mathrm{Hg}$ exposure influenced several 


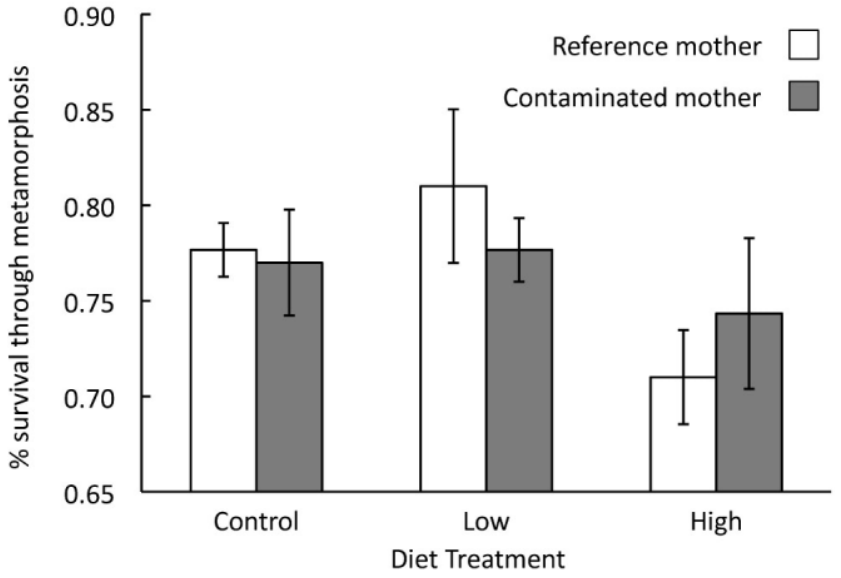

Fig. 2. Percentage survival (mean \pm standard error) of American toads through metamorphosis. Larvae from either reference or $\mathrm{Hg}$-exposed mothers were fed control diet with no added $\mathrm{Hg}$, low- $\mathrm{Hg}$ diet $(2.5 \mu \mathrm{g} / \mathrm{g}$ total $\mathrm{Hg}$ dry wt), or high-Hg diet (10.1 $\mu \mathrm{g} / \mathrm{g}$ total $\mathrm{Hg}$ dry wt). Dietary $\mathrm{Hg}$ had a marginal effect on survival $(p=0.077)$.

endpoints in the component tests. Specifically, animals from $\mathrm{Hg}$-exposed mothers had significantly lower body mass at GS 42 (Fig. 3A; $F_{1,30}=14.1, p=0.001$ ) and at GS 46 (Fig. 3B; $\left.F_{1,30}=13.1, p=0.001\right)$. On average, animals from $\mathrm{Hg}$ mothers were approximately $14 \%$ smaller at GS 42 and GS 46 than were those from reference mothers. Animals from $\mathrm{Hg}$-exposed mothers also took 6\% longer to resorb their tails completely (Fig. 4; $\left.F_{1,30}=21.9, p<0.001\right)$. Finally, the proportion of animals having spinal malformations at GS 42 was 2.5 times greater for animals from $\mathrm{Hg}$-exposed mothers (Fig. 5; $F_{1,30}=18.5$, $p<0.001)$. We found no significant effect of maternal $\mathrm{Hg}$ on survival to GS 46 ( $\left.F_{1,30}=0.00, p=0.926\right)$. We also found no significant effects of diet, maternal $\mathrm{Hg}$ exposure, or their interaction on the overall length of the larval period (range across treatments: 49.2-62.1 days; diet: $F_{2,30}=1.04, p=0.59$; maternal $\mathrm{Hg}$ exposure: $F_{1,30}=1.35, p=0.25$; interaction: $\left.F_{2,30}=0.09, p=0.956\right)$.

The pattern of variation in hopping performance across treatments was similar to that of the body size differences (Fig. 6). This likely was due to the significant positive correlation between body size and mean hop length of the recently metamorphosed toads $\left(F_{1,29}=8.1, p=0.008\right)$. Consequently, we found no significant effect of diet, maternal $\mathrm{Hg}$ exposure, or their interaction on the mean hop length of recently metamorphosed toads when body size was included as a covariate in the model (diet: $F_{2,29}=0.85, p=0.44$; maternal $\mathrm{Hg}$ exposure: $F_{1,29}=0.04, p=0.84$; interaction: $\left.F_{2,29}=0.63, p=0.54\right)$.

\section{DISCUSSION}

Amphibians with biphasic life histories transition from aquatic to terrestrial habitats over the course of their lives [2]. This dual reliance on separate habitat types by many amphibians may place them in double jeopardy from hazards that can affect both habitats [3]. Consequently, they provide an ideal opportunity for examining the combined and differential effects of contaminant exposure by multiple pathways. The present study evaluated the double jeopardy hypothesis by examining the individual and interactive effects of contaminant exposure from both terrestrial (by maternal effects) and aquatic (by direct dietary or aqueous exposure) environments in larval American toads. Although no support for interactive effects of
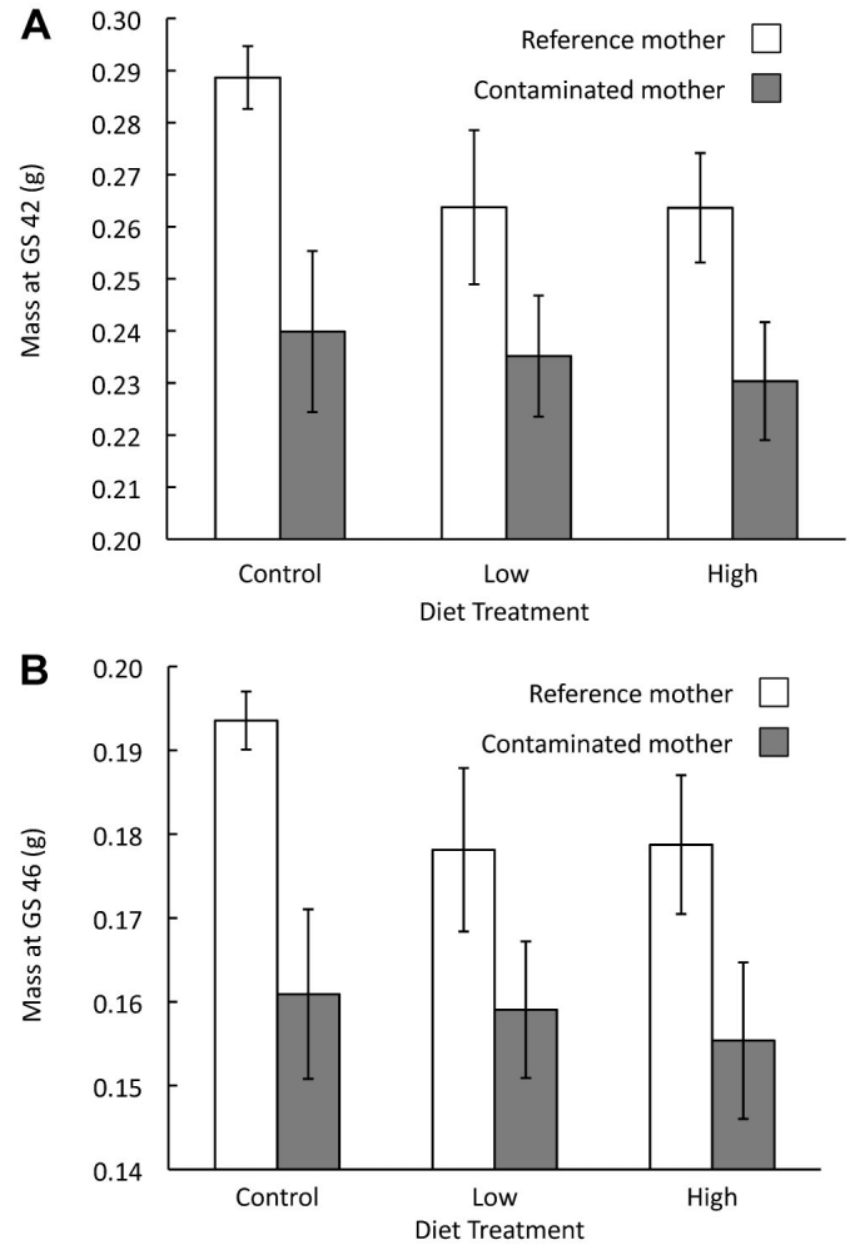

Fig. 3. Mass (mean \pm standard error) of larval and recently metamorphosed American toads at Gosner stage (GS) 42 (A) and GS 46 (B). Larvae from either reference or mercury $(\mathrm{Hg})$-exposed mothers were fed control diet with no added $\mathrm{Hg}$, low- $\mathrm{Hg}$ diet $(2.5 \mu \mathrm{g} / \mathrm{g}$ total $\mathrm{Hg}$ dry wt), or high- $\mathrm{Hg} \operatorname{diet}(10.1 \mu \mathrm{g} /$ $\mathrm{g}$ total $\mathrm{Hg}$ dry wt). Offspring from $\mathrm{Hg}$-exposed mothers had significantly reduced mass at both stages $(p=0.001)$.

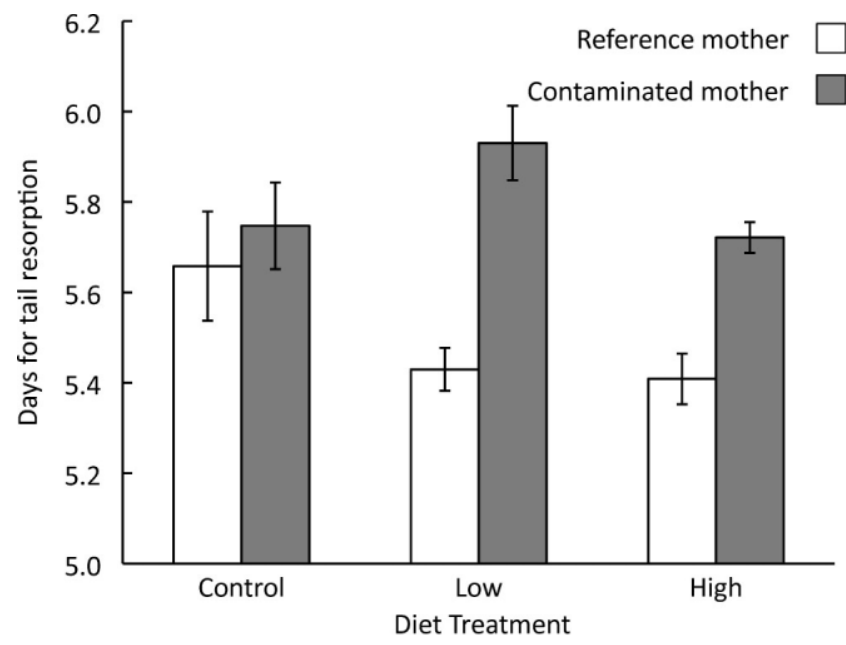

Fig. 4. Number of days required (mean \pm standard error) for complete tail resorption (days between Gosner stages 42 and 46) in larval American toads. Larvae from either reference or $\mathrm{Hg}$-exposed mothers were fed control diet with no added $\mathrm{Hg}$, low- $\mathrm{Hg}$ diet $(2.5 \mu \mathrm{g} / \mathrm{g}$ total $\mathrm{Hg}$ dry wt), or high- $\mathrm{Hg}$ diet $(10.1 \mu \mathrm{g} / \mathrm{g}$ total $\mathrm{Hg}$ dry wt). Offspring from $\mathrm{Hg}$-exposed mothers took significantly longer to complete metamorphosis $(p<0.001)$. 


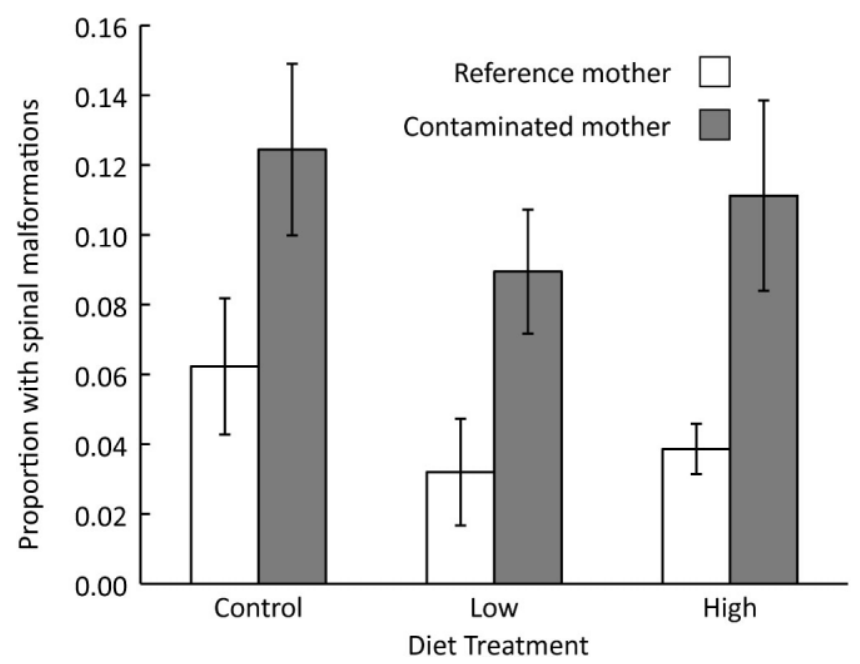

Fig. 5. Proportion (mean \pm standard error) of larval American toads having spinal malformations at Gosner stage 42. Larvae from either reference or $\mathrm{Hg}$ exposed mothers were fed control diet with no added $\mathrm{Hg}$, low-Hg diet $(2.5 \mu \mathrm{g} /$ $\mathrm{g}$ total $\mathrm{Hg}$ dry wt), or high-Hg diet (10.1 $\mu \mathrm{g} / \mathrm{g}$ total $\mathrm{Hg}$ dry wt). Offspring from $\mathrm{Hg}$-exposed mothers had significantly more spinal malformations on average $(p<0.001)$.

these two exposure pathways was found in the present study, the results demonstrate that amphibians do face negative impacts from contaminant exposure in both environments, thereby posing a double jeopardy to species with biphasic life histories.

The present study was designed to partition the maternal and dietary effects of $\mathrm{Hg}$ exposure to examine effects on offspring body size, survival, timing of metamorphosis, physical performance, and malformation frequency. The effects of maternal $\mathrm{Hg}$ exposure in reducing body size and delaying tail resorption were similar in effect size and direction to results from a separate study published earlier [11]. In contrast, only a marginal effect of diet on survival was observed in the present study, whereas in an earlier study there were significant negative effects of dietary $\mathrm{Hg}$ on body size and significantly increased mortality in the interaction of maternally exposed

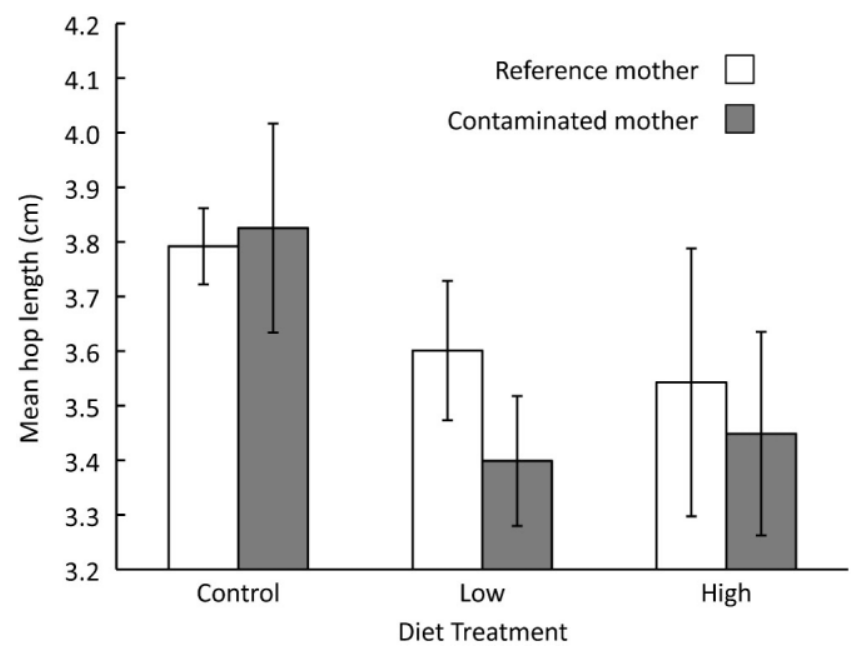

Fig. 6. Hop length (mean \pm standard error) of recently metamorphosed American toads. Toads from either reference or $\mathrm{Hg}$-exposed mothers were fed control diet with no added $\mathrm{Hg}$, low- $\mathrm{Hg}$ diet $(2.5 \mu \mathrm{g} / \mathrm{g}$ total $\mathrm{Hg}$ dry wt), or high- $\mathrm{Hg}$ diet $(10.1 \mu \mathrm{g} / \mathrm{g}$ total $\mathrm{Hg}$ dry wt) as larvae. Hop length was significantly correlated with body size $(p=0.008)$ but was not affected by maternal $\mathrm{Hg}$, diet, or their interaction after controlling for body size $(p>0.4)$. larvae fed high dietary $\mathrm{Hg}$ [11]. The greater food rationing in the present study ( $9 \%$ of body mass per day compared with $6 \%$ used by Bergeron et al. [11]) might have masked some of the physiological deficits that become evident with more restrictive rationing, thus diminishing dietary effects in the present study. For example, Hopkins et al. [26] reported that lower food rationing led to stronger effects on survival and growth in chubsuckers (Erimyzon sucetta) exposed to coal ash than did higher rationing. Alternatively, despite the large number of larvae used in the present study, the experimental unit was the average of each communal bin, so lower statistical power might have limited our ability to detect dietary effects.

The reduced body size, longer tail resorption time, and increased malformation frequency that resulted from maternal $\mathrm{Hg}$ exposure likely have implications for individual fitness. For example, smaller body size caused by maternal $\mathrm{Hg}$ was tied to reduced hop length in the present study, a consequence that could not be examined in previous work [11] and that can affect an animal's ability to forage or evade predators [27]. Body size at metamorphosis is therefore frequently linked to postmetamorphic survival and lifetime reproductive success in amphibians [28,29]. A follow-up study will examine postmetamorphic survival of the offspring used in the present study over an additional year in the terrestrial environment. Similar to reductions in body size, the effect of maternal $\mathrm{Hg}$ on increased frequency of spinal malformations may also reduce individual fitness. Larvae with malformations swim more slowly and are more likely to succumb to predation than normal larvae $[10,12,30]$. Such developmental problems are likely related to the reduced swimming performance in maternally exposed larvae found in an earlier study [11]. However, frequencies of obvious malformations are often low, and no gross aberrations were found in the prior study because of the small number of larvae studied ( 150 vs 1,800 total larvae). Spinal malformations in amphibian larvae have been previously linked to dietary $\mathrm{Hg}$ and exposure to coal ash pollutants [12,31], and developmental abnormalities and altered swimming in amphibian larvae have also been linked to maternal exposure to trace elements derived from coal fly ash [6]. Finally, maternal $\mathrm{Hg}$ exposure increased the duration of metamorphic climax, a period of increased vulnerability for immunological [32], energetic [33], and ecological reasons, a consequence that may increase mortality risk in natural settings.

Previous studies of other species have examined the individual and interactive effects of maternal and posthatching contaminant exposure on growth and survival of offspring and have also found strong maternal effects from contaminants. For example, Nye et al. [34] studied the effects of sediment contaminated with polycyclic aromatic hydrocarbons, trace elements, and tributyltin on larval mummichogs, Fundulus heteroclitus, to determine the individual and interactive effects of maternal and direct contaminant exposure. They found that maternal exposure had an effect on egg composition and a stronger effect on larval growth rate than did larval exposure. Eisenreich et al. [35] also studied the individual and interactive effects of maternal and dietary PCB exposure on snapping turtles (Chelydra serpentina) and found that maternal exposure was more predictive of latent mortality, whereas dietary exposure better explained reductions in standard metabolic rates. These studies and results of the present study provide evidence that the type of negative effects observed will depend in part on the route of exposure, with maternal effects alone sometimes having more diverse or greater effects on offspring than other exposure routes. 
The ecological or physiological effects of $\mathrm{Hg}$ on wildlife have historically been well studied, but fewer studies have been conducted on amphibians [13,36]. Beckvar et al. [37] reviewed 10 studies of fish and suggested a whole-body tissue thresholdeffect level of $200 \mathrm{ng} / \mathrm{g}$ (wet wt) $\mathrm{MeHg}$ for juveniles and adults. The present study provides evidence of adverse maternal effects in American toad offspring from mothers with whole-body concentrations of $347 \mathrm{ng} / \mathrm{g} \mathrm{MeHg}$ wet wt (see Todd et al. [10] for calculations), a level exceeding the threshold established by Beckvar et al. [37]. However, Weiner and Spry [38] concluded that sublethal effects in fish embryos and larvae could occur at 1 to $10 \%$ of adult concentrations (2-20 ng/g wet wt $\mathrm{MeHg}$ based on Beckvar et al. [37]). Matta et al. [39] also found a sublethal effect of reduced reproductive success in offspring of maternally exposed mummichogs when egg $\mathrm{MeHg}$ concentrations were as low as $10 \mathrm{ng} / \mathrm{g}$ wet weight. In the present study, adverse maternal effects were observed in offspring that hatched from eggs with an estimated $\mathrm{MeHg}$ concentration of $3.6 \mathrm{ng} / \mathrm{g}$ wet weight (see Todd et al. [10] for calculations), a concentration toward the low end of the concentrations expected to cause harm in fish.

The tissue $\mathrm{Hg}$ concentrations in recently metamorphosed toads in the current experimental study, as well as those in a similar companion study in which toads were reared individually [11], closely matched concentrations in field-collected animals from the study site used by Bergeron et al. [9]. American toad larvae collected from contaminated portions of the South River had THg tissue concentrations that averaged $2.1 \mu \mathrm{g} / \mathrm{g}$ (dry wt) at GS 28 to GS 32 [9]. In the present study, dietary $\mathrm{Hg}$ concentrations of $2.5 \mu \mathrm{g} / \mathrm{g}$ and $10.1 \mu \mathrm{g} / \mathrm{g}$ THg (dry wt) resulted in respective whole-body $\mathrm{THg}$ tissue concentrations that averaged $1.1 \mu \mathrm{g} / \mathrm{g}$ (dry wt) and $3.7 \mu \mathrm{g} / \mathrm{g}$ (dry wt) at GS 46 , after the significant mass loss that occurs during metamorphosis $[21,31,40]$. In the companion study, recently metamorphosed toads that were raised individually rather than communally had whole-body $\mathrm{THg}$ tissue concentrations that averaged $0.8 \mu \mathrm{g} / \mathrm{g}$ (dry wt) and $1.7 \mu \mathrm{g} / \mathrm{g}$ (dry wt) for the low- $\mathrm{Hg}$ and high-Hg diets, respectively [11]. The greater food rationing for the larvae raised communally in the present study compared with those raised individually in the earlier study likely is responsible for the observed differences in THg tissue concentrations; when larvae are fed greater amounts of food with dietary $\mathrm{Hg}$ they attain larger sizes and accumulate more $\mathrm{Hg}$ [11].

It is noteworthy that accumulation of $\mathrm{MeHg}$ and $\mathrm{HgII}$ in offspring tissues was greater in larvae from $\mathrm{Hg}$-exposed mothers than in those from reference mothers. This difference was most pronounced in the high- $\mathrm{Hg}$ diet treatment. The difference in accumulated $\mathrm{Hg}$ between larvae from $\mathrm{Hg}$-exposed and reference mothers is too large to be accounted for by maternal contributions alone because of considerable larval growth and resulting dilution of initial $\mathrm{Hg}$ present from maternal sources. Thus, larvae from $\mathrm{Hg}$-exposed mothers must have accumulated $\mathrm{Hg}$ differently, possibly as a consequence of their embryonic exposure. The mechanisms leading to such a pattern are unclear, but the increased accumulation of $\mathrm{Hg}$ in individuals exposed embryonically suggests that offspring exposed maternally are at greater risk of later contaminant exposure as a result of enhanced bioaccumulation.

The present study demonstrates that amphibians do indeed face a double jeopardy of contaminant exposure from terrestrial and aquatic environments; both exposure pathways had adverse effects on developing offspring. However, there was no strong support for interactive or synergistic consequences of combined terrestrially and aquatically derived $\mathrm{Hg}$ exposure. Primarily, these results indicate that maternal contaminant exposure from terrestrial adults had more widespread effects on offspring than did direct exposure of larvae in the aquatic environment. Given the fact that other studies have also demonstrated that maternal exposure has a greater influence on offspring health than dietary exposure [34,35], it is important that future studies consider the maternal effects on offspring health. The present study also indicates that all possible routes of exposure over an organism's life history must be examined to provide a comprehensive understanding of the ecological consequences of habitat contamination. Ultimately, it will be important in future work to determine whether carryover effects exist in metamorphosed individuals that transition to the terrestrial environment and whether additional terrestrial exposure in the postmetamorphic environment exacerbates the negative effects seen here.

Acknowledgement-We thank J. Burke, D. Cristol, K. Carlson-Drexler, A. Condon, M. Howie, K. McCaleb, J. McPherson, C. Ramos, J. Schmerfeld, the South River Science Team, H. Wada, and Waynesboro Parks and Recreation Department for assistance. Financial support was provided by E.I. DuPont de Nemours, by Virginia Polytechnic Institute and State University, and by the National Science Foundation (NSF IOB-0615361). C.M. Bergeron was supported by the U.S. Environmental Protection Agency (U.S. EPA) STAR Graduate Fellowship (FP-9170040-1). The U.S. EPA has not officially endorsed this publication, and the views expressed herein may not reflect the views of the U.S. EPA. Research was completed with oversight from the South River Science Team, which is a collaboration of state and federal agencies, academic institutions, and environmental interests. Collecting permits and IACUC permission were obtained through W.A. Hopkins at Virginia Polytechnic Institute and State University

\section{REFERENCES}

1. Yates MA, Fuller MR, Henny CJ, Seegar WS, Garcia J. 2010. Wintering area DDE source to migratory white-faced ibis revealed by satellite telemetry and prey sampling. Ecotoxicology 19:153-162.

2. Semlitsch RD. 2008. Differentiating migration and dispersal processes for pond-breeding amphibians. J Wildl Manag 72:260-267.

3. Dunson WA, Wyman RL, Corbett ES. 1992. A symposium on amphibian declines and habitat acidification. $J$ Herpetol 26:349-352.

4. Sparling DW, Linder G, Bishop CA, Krest SK, eds. 2010. Ecotoxicology of Amphibians and Reptiles, 2nd ed. CRC, Boca Raton, FL, USA.

5. Hothem RL, Jennings MR, Crayon JJ. 2010. Mercury contamination in three species of anuran amphibians from the Cache Creek Watershed, California, USA. Environ Monit Assess 163:443-448.

6. Hopkins WA, DuRant SE, Staub BP, Rowe CL, Jackson BP. 2006. Reproduction, embryonic development, and maternal transfer of contaminants in the amphibian Gastrophryne carolinensis. Environ Health Perspect 114:661-666.

7. Bergeron CM, Bodinof CM, Unrine JM, Hopkins WA. 2010. Bioaccumulation and maternal transfer of mercury and selenium in amphibians. Environ Toxicol Chem 29:989-997.

8. Bernardo J. 1996. Maternal effects in animal ecology. Am Zool 36:83105 .

9. Bergeron CM, Bodinof CM, Unrine JM, Hopkins WA. 2010. Mercury accumulation along a contamination gradient and nondestructive indices of bioaccumulation in amphibians. Environ Toxicol Chem 29:980988.

10. Todd BD, Bergeron CM, Hepner MJ, Burke JN, Hopkins WA. 2011. Does maternal exposure to an environmental stressor affect offspring response to predators? Oecologia 166:283-290.

11. Bergeron CM, Hopkins WA, Todd BD, Hepner MJ, Unrine JM. 2011. Interactive effects of maternal and dietary mercury exposure have latent and lethal consequences for amphibian larvae. Environ Sci Technol 45:3781-3787.

12. Hopkins WA, Congdon JD, Ray JK. 2000. Incidence and impact of axial malformations in larval bullfrogs (Rana catesbeiana) developing in sites polluted by a coal burning power plant. Environ Toxicol Chem 19:862868 .

13. Eisler R. 2006. Mercury Hazards to Living Organisms. CRC, Boca Raton, FL, USA.

14. Crump KL, Trudeau VL. 2009. Mercury-induced reproductive impairment in fish. Environ Toxicol Chem 28:895-907. 
15. Tan SW, Meiller JC, Mahaffey KR. 2009. The endocrine effects of mercury in humans and wildlife. Crit Rev Toxicol 39:228-269.

16. Kalb HJ, Zug GR. 1990. Age estimates for a population of American Toads, Bufo americanus (Salientia: Bufonidae), in Northern Virginia. Brimleyana 16:79-86.

17. Bergeron CM, Husak JF, Unrine JM, Romanek CS, Hopkins WA. 2007. Influence of feeding ecology on blood mercury concentrations in four turtle species. Environ Toxicol Chem 26:1733-1741.

18. Cristol DA, Brasso RL, Condon AM, Fovargue RE, Friedman SL, Hallinger KK, Monroe AP, White AE. 2008. The movement of aquatic mercury through terrestrial food webs. Science 320:335.

19. Wada H, Yates DE, Evers DC, Taylor RJ, Hopkins WA. 2010. Tissue mercury concentrations and adrenocortical responses of female big brown bats (Eptesicus fuscus) near a contaminated river. Ecotoxicology 19:1277-1284.

20. Unrine JM, Jagoe CH. 2004. Dietary mercury exposure and bioaccumulation in southern leopard frog (Rana sphenocephala) larvae. Environ Toxicol Chem 23:2956-2963.

21. Unrine JM, Jagoe CH, Brinton AC, Brant HA, Garvin NT. 2005. Dietary mercury exposure and bioaccumulation in amphibian larvae inhabiting Carolina bay wetlands. Environ Pollut 135:245-253.

22. Goater CP, Semlitsch RD, Bernasconi MV. 1993. Effects of body size and parasite infection on the locomotory performance of juvenile toads, Bufo bufo. Oikos 66:129-136.

23. U.S. Environmental Protection Agency. 1998. Method 7473: Mercury in solids and solutions by thermal decomposition, amalgamation, and atomic absorption spectrometry, Washington, DC.

24. Shade CW. 2008. Automated simultaneous analysis of monomethyl and mercuric $\mathrm{Hg}$ in biotic samples by $\mathrm{Hg}$-thiourea complex liquid chromatography following acidic thiourea leaching. Environ Sci Technol 42:6604-6610.

25. Dytham C. 2003. Choosing and Using Statistics: A Biologist's Guide, 2nd ed. Blackwell Science, Malden, MA, USA.

26. Hopkins WA, Snodgrass JW, Roe JH, Staub BP, Jackson BP, Congdon JD. 2002. Effects of food ration on survival and sublethal responess of lake chubsuckers (Erimyzon sucetta) exposed to coal combustion wastes. Aquat Toxicol 57:191-202.

27. John-Adler HB, Morin PJ. 1990. Effects of larval density on jumping ability and stamina in newly metamorphosed Bufo woodhousii fowleri. Copeia 1990:856-860.
28. Berven KA, Gill DE. 1983. Interpreting geographic variation in lifehistory traits. Am Zool 23:85-97.

29. Scott DE. 1994. The effect of larval density on adult demographic traits in Ambystoma opacum. Ecology 75:1383-1396.

30. Raimondo SM, Rowe CL, Congdon JD. 1998. Exposure to coal ash impacts swimming performance and predator avoidance in larval bullfrogs (Rana catesbeiana). J Herpetol 32:289-292.

31. Unrine JM, Jagoe CH, Hopkins WA, Brant HA. 2004. Adverse effects of ecologicaly relevant dietary mercury exposure in southern leopard frog (Rana sphenocephala) larvae. Environ Toxicol Chem 23:29642970.

32. Todd BD. 2007. Parasites lost? An overlooked hypothesis for the evolution of alternative reproductive straegies in amphibians. Am Nat 170:793-799.

33. Beck CW, Congdon JD. 2003. Energetics of metamorphic climax in the southern toad (Bufo terrestris). Oecologia 137:344-351.

34. Nye JA, Davis DD, Miller TJ. 2007. The effect of maternal exposure to contaminated sediment on the growth and condition of larval Fundulus heteroclitus. Aquat Toxicol 82:242-250.

35. Eisenreich KM, Kelly SM, Rowe CL. 2009. Latent mortality of juvenile snapping turtles from the upper Hudson River, New York, exposed maternally and via the diet to polychlorinated biphenyls (PCBs). Environ Sci Technol 43:6052-6057.

36. Scheuhammer AM, Meyer MW, Sandheinrich MB, Murray MW. 2007. Effects of environmental methylmercury on the health of wild birds, mammals, and fish. Ambio 36:12-18.

37. Beckvar N, Dillon TM, Read LB. 2005. Approaches for linking wholebody fish tissue residues of mercury or DDT to biological effects thresholds. Environ Toxicol Chem 24:2094-2105.

38. Weiner JG, Spry DJ. 1996. Toxicological significance of mercury in freshwater fish. In Beyer WN, Heinz GH, Redmon-Norwood AW, eds, Environmental Contaminants in Wildlife: Interpreting Tissue Concentrations. Lewis, Boca Raton, FL, USA, pp 297-340.

39. Matta MB, Linse J, Cairncross C, Francendese L, Kocan RM. 2001 Reproductive and transgenerational effects of methylmercury or Aroclor 1268 on Fundulus heteroclitus. Environ Toxicol Chem 20: 327-335.

40. Downie JR, Bryce R, Smith J. 2004. Metamorphic duration: an understudied variable in frog life histories. Biol J Linn Soc 83:261272. 